\title{
A United Allocation Method of Spare Parts and Ground Maintenance Equipment for Civil Aircraft
}

\author{
Li Yongkai ${ }^{1, a}$, Feng Yunwen ${ }^{1}$, Xue Xiaofeng ${ }^{1}$ and Lu Cheng ${ }^{1}$ \\ ${ }^{1}$ School of Aeronautics, Northwestern Polytechnical University, 7100772 Xian, China
}

\begin{abstract}
Aimed at multi-echelon inventory allocation problem with finite repair capacity for civil aircraft, a united planning method based on queuing theory and Vari-Metric model is presented to deploy the aircraft spare parts and ground maintenance equipment. Through the analysis of actual engineering, the effect of repair time is quantified by the number of maintenance equipment. On this basis, the available of fleet and the cost expense are selected as the objective and constraint respectively, marginal analysis method is set as the optimization, a new allocation scheme which was suit to civil aircraft's maintenance resources is put forward. By applied examples analysis, it is shows that this method is reasonable and feasible.
\end{abstract}

\section{Introduction}

Due to the rapid development of high-tech equipment, maintenance resources (spare parts and ground maintenance equipment) to ensure the normal use of the civil aircraft has been attached more and more importance. With complex equipment lead to fast-rising prices of spare parts and repair facilities, the contradiction of outlay and resources shortage become more prominent if we allocate maintenance resources according to the traditional method. Therefore, in order to ensure the timeliness of maintenance tasks and reduce operating costs for civil aircraft, we need to make reasonable allocation for civil aircraft's maintenance resources to seek optimal cost-effectiveness between fleet availability and cost expense of resources.

In foreign countries, study on maintenance resources allocation carried out earlier than China. The classical Metric model is proposed by Sherbrooke[1], which laid a foundation for multi-echelon inventory allocation theory. Muckstadt[2] established an inventory management method for the multiorder multi-echelon case, i.e. the Mod-Metric system model. Graves[3] put forward Vari-Metric model to solve the problem of multi-echelon multi-indenture spare parts inventory control. The existing researches about multi-echelon inventory allocation had been applied to various managements of maintenance resources, however, previous studies were based on the assumption of infinite repair capacity, and the maintenance ability of each location is limited in the practical engineering. These methods failed to consider the interaction between the number of maintenance equipment and maintenance ability.

In this paper, the assumption of infinite repair capacity is relaxed and the effect of repair time is quantified by the number of maintenance equipment based on $\mathrm{M} / \mathrm{M} / \mathrm{c}$ queuing theory. According to

\footnotetext{
${ }^{\mathrm{a}}$ Corresponding author : 1yk56820@hotmail.com
} 
the Vari-Metric method, a calculation mode for fleet availability of civil aircraft is established. Based on that, this study put forward a united allocation method of spare parts and ground maintenance equipment for civil aircraft, resources allocation scheme is also obtained. In addition, the influence of the inventory scheme between limited and infinite repair capacity is evaluated.

\section{Model descriptions}

In general, the maintenance points of aircraft is regarded as two-echelon inventory model, respectively, the Local Warehouse (LW) and the Central Department (CD). When the parts on the aircraft are in trouble, broken parts will be replaced if spare parts are available on the LW, otherwise, order a spare part to the $\mathrm{CD}$ with a $(\mathrm{S}-1, \mathrm{~S})$ replenishment policy. The invalid parts are sent to repair shop at the CD unless there have adequate repair capacity on the LW. Repaired parts will act as new spare parts and replenish stocks.

It should follow the principle of queuing theory in repair: the invalid parts can be repaired immediately if there have free maintenance equipment, or waiting to repair until the free maintenance facilities occurred. Which means that the maintenance process of invalid parts satisfying a first-come, first-serve(FCFS) basis. The replacement and maintenance process of the aircraft parts is shown in figure 1.

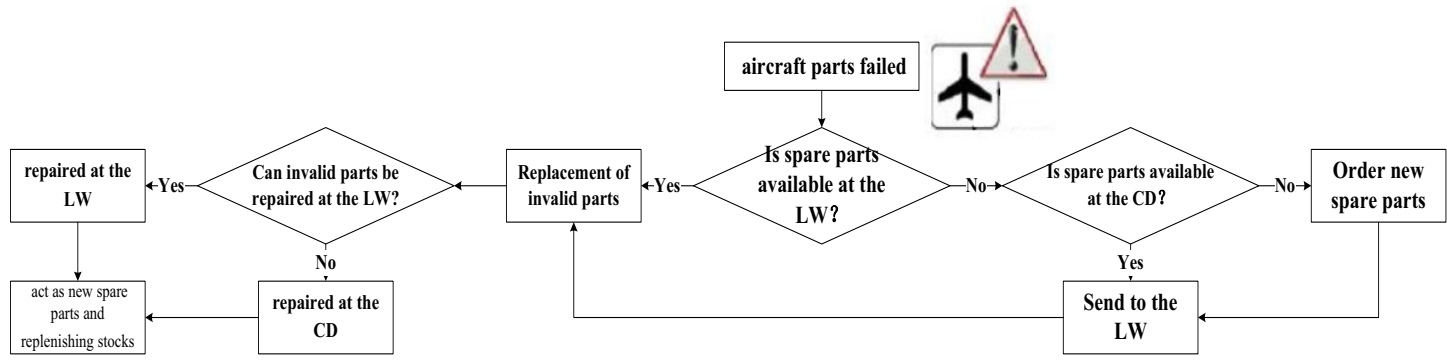

Figure 1 The replacement and maintenance process of the aircraft parts

In order to simplify the modeling process, there are some reasonable assumptions for united allocation method of spare parts and ground maintenance equipment:

- The failure of aircraft parts follows the Poisson process.

- The invalid parts can be repaired perfectly.

- Any aircraft part has a independent mean-time-between-maintenance (MTBM).

- There is no lateral supply.

For a better expression of the model, the variables are listed as follows:

$i \quad$ spare parts number. $i=1,2,3 \cdots, n$

$j$ maintenance points number. CD: $j=0, \mathrm{LW}: j=1,2,3 \cdots, m$

$k$ maintenance equipment number. $k=1,2,3 \cdots, 1$

$\mathrm{S}_{q} \quad$ the allocation scheme. Spare part: $q=0$, maintenance equipment: $q=1$

$C_{q} \quad$ purchase price. Spare part: $q=0$, maintenance equipment: $q=1$

$r$ air route number. $r=1,2,3 \ldots$

$D_{r j}$ flight mileage through maintenance point $j$ at air route $r$.

$M_{i}$ the total demand of spare parts $i$

$m_{i j} \quad$ the demand of spare parts $i$ at maintenance point $j$.

$r_{j} \quad$ repair probability at maintenance point $j$.

$T_{i j} \quad$ the repair time of spare parts $i$ at maintenance point $j$.

$\mu_{i j}$ the average demand of spare parts $i$ getting from maintenance and resupply at maintenance 
point $j$.

$P_{i j}$ the steady state probability of spare parts $i$ getting from maintenance and resupply at maintenance point $j$.

$O_{i j} \quad$ order and ship time of spare parts $i$ from the $\mathrm{CD}$ to maintenance point $j$.

$f_{i j} \quad$ the fraction of all demands of spare parts $i$ at the LW $j$.

\section{Estimating the demand of spare parts}

\subsection{The demand model of spare parts}

The basic formula of spare parts demand is:

$$
\begin{gathered}
M=\text { A.I.P }+I . N \sqrt{\text { A.I.P }} \\
\text { A.I.P }=\text { S.V. } \times \text { C.T. } / T .
\end{gathered}
$$

Where: $M$-the demand number of spare parts, A.I.P - the average number of spare parts need to be repaired, S.V.-repair rate per year, C.T.-repair time, T. - annual working days, I.N - index number, represents the level of security.

\subsection{The demand for each maintenance point}

For the LW maintenance points, the demand of spare parts can be determined according to the percentage of flight mileage through the LW from the total route. Define $D_{r}$ as the total route of air route $r$, and $m^{r}{ }_{i j}$ as the demand caused by air route $r$ of spare parts $i$ at maintenance point $j$ :

$$
m^{r}{ }_{i j}=\frac{D_{r j}}{D_{r}} M_{i}
$$

The total demand $m_{i j}$ consist of the sum of demand for all routes that pass through the LW

$$
m_{i j}=\sum m_{i j}^{r}
$$

For the CD maintenance points, the demand of spare parts equal to the number of spare parts that cannot be repaired at the LW.

$$
m_{i 0}=\sum m_{i j}\left(1-\mathrm{r}_{j}\right)
$$

\section{A united allocation method of maintenance resources for civil aircraft}

\subsection{The construction of multi-echelon spare parts inventory model}

According to the classic METRIC theory, the following relationships exist in inventory level[4]:

$$
\mathrm{S}=\mathrm{OH}+\mathrm{DI}-\mathrm{BO}
$$

$S$ is the inventory level, $O H$ is existing inventory, $D I$ is the number of spare parts getting from maintenance and resupply, $B O$ is the shortage number of spare parts. When using $(\mathrm{S}-1, \mathrm{~S})$ inventory strategy, the value of $S$ is constant, $O H, D I$ and $B O$ are in a state of dynamic equilibrium. Therefore, the expectation $E B O\left(\mathrm{~S}_{0}\right)$ and variance $V B O\left(\mathrm{~S}_{0}\right)$ of spare parts shortage can be expressed by the following formulas when the value of $\mathrm{OH}$ is $\mathrm{S}_{0}$ : 


$$
\begin{gathered}
E B O\left(\mathrm{~S}_{0}\right)=\mathrm{P}\left(\mathrm{DI}=\mathrm{S}_{0}+1\right)+2 \mathrm{P}\left(\mathrm{DI}=\mathrm{S}_{0}+2\right)+\ldots=\sum_{X=S_{0}+1}^{\infty}\left(\mathrm{x}-\mathrm{S}_{0}\right) P(\mathrm{DI}=x) \\
V B O\left(S_{O}\right)=E\left[B O^{2}\left(S_{0}\right)\right]+\left[E B O\left(S_{0}\right)\right]^{2}
\end{gathered}
$$

Where, $P(\mathrm{DI}=x)$ is the probability that the number of spare parts getting from maintenance and resupply is $x$. Next, calculating $P(\mathrm{DI}=x)$ at the $\mathrm{LW}$ and $\mathrm{CD}$ respectively.

According to the Palm theorem, the number of spare parts getting from maintenance and resupply followed from Boson distribution with $m_{i 0} T_{i 0}$ mean. So the average demand $\mu_{i 0}$ and steady state probability $P_{i 0}$ for the number of spare parts getting from maintenance and resupply can be expressed by the following:

$$
\begin{gathered}
\mu_{i 0}=m_{i 0} T_{i 0} \\
P_{i 0}(x)=\operatorname{Poisson}\left(x, \mu_{i 0}\right)
\end{gathered}
$$

The expectation $E B O_{i 0}(\mathrm{~S})$ and variance $V B O_{i 0}(\mathrm{~S})$ of spare parts shortage at the $\mathrm{CD}$ can be derived from the formulas (6), (7) and (9).

The average demand of spare parts getting from maintenance and resupply at the LW $\mu_{i j}$ consists of two parts: one is the fault parts for maintenance at the LW, and the other is the fault parts sent to the $\mathrm{CD}$ due to the lack of maintenance capability at the LW:

$$
\mu_{i j}=m_{i j}\left(\mathrm{r}_{i j} \mathrm{~T}_{i j}+\left(1-r_{i j}\right)\left\{O_{i j}+E B O_{i 0} / m_{i 0}\right\}\right)
$$

The variance for the number of spare parts getting from maintenance and resupply $\operatorname{Var}_{i j}(S)$ can be expressed by the following formula:

$$
\operatorname{Var}_{i j}(S)=m_{i j}\left[r_{i j} T_{i 0}+\left(1-r_{i j}\right) O_{j}\right]+f_{i j}\left(1-f_{i j}\right) E B O_{i 0}(S)+f_{i j}^{2} V B O_{i 0}(S)
$$

Where

$$
f_{i j}=\frac{m_{i j}\left(1-r_{i j}\right)}{m_{i 0}}
$$

The steady state probability of $\mathrm{DI}=x$ at the LW depends on the ratio of mean and variance $p=\mu_{i j} / \operatorname{Var}_{i j}(S)$. If $p>1$, the number of spare parts getting from maintenance and resupply followed a negative binomial distribution; else if $p \approx 1$, this number according to Poisson distribution; and if $p<1$, selecting binomial distribution. So we can get the steady state probability $P_{i j}$, furthermore, we obtain the expectation $E B O_{i j}(\mathrm{~S})$ and variance $V B O_{i j}(\mathrm{~S})$ of spare parts shortage at the LW.

The total expectation of spare parts shortage consists of the expectation at all maintenance points:

$$
E B O_{i}(\mathrm{~S})=\sum_{i=1}^{n} E B O_{i 0}(S)+\sum_{i=1}^{n} \sum_{j=1}^{m} E B O_{i j}(S)
$$

The relationship between fleet availability $A$ and the total expectation of spare parts shortage $E B O_{i}(\mathrm{~S})$ is:

$$
A=100 \prod_{i=1}^{n}\left\{1-E B O_{i}(\mathrm{~S}) / N Z_{i}\right\}^{Z_{i}}
$$

Where, $Z_{i}$ is the installed number at a plane, $N$ is the number of aircraft in a fleet. Thus, the maximum availability of fleet equal to the minimum value for the expectation of spare parts shortage.

The investment cost of all maintenance resources $C$ is composed of two parts: the cost of purchasing spare parts and the cost of the maintenance equipment: 


$$
C=\sum_{i=1}^{n} c_{0 i} S_{0 i}+\sum_{k=1}^{l} c_{1 k} S_{1 k}
$$

Where, $c_{0 i}, S_{0 i}$ are the purchase price and allocation scheme of $i-t$ th spare parts, $c_{1 k}, S_{1 k}$ are the purchase price and allocation scheme of $k-t h$ maintenance equipment.

Through the above analysis, the available of fleet and the cost expense are selected as the objective and constraint respectively, a multi-echelon inventory allocation method is put forward:

$$
\begin{aligned}
& \min E B O(S) \\
& \text { s.t. } \quad C \leq C_{0}
\end{aligned}
$$

\subsection{The effect of ground maintenance equipment on repair time}

Based on the multi-service model of queuing theory, the problem of maintenance resources allocation under the condition of limited maintenance capacity is solved. The following are the assumptions of the repair process

- The arrival interval of fault parts followed with negative exponent distribution (Parameters is $\lambda$ ).

- The repair time followed with negative exponent distribution (Parameters is $\mu$ ).

- System capacity: infinite.

- Queue length: infinite.

- Serve regulation: first-come-first-served (FCFS).

Define $\rho=\frac{\lambda}{\mu}, \rho_{s}=\frac{\lambda}{k \mu}, k$ is the number of maintenance equipment. In order to avoid the queue is lengthening, the repair capacity per unit time should be greater than the number of failures, i.e., $\rho_{s}<1$

The probability that a fault part does not have to wait for service when it arrives $p_{0}$ is:

$$
p_{0}=\left[\sum_{n=0}^{k-1} \frac{\rho^{n}}{n !}+\frac{\rho^{k}}{k !\left(1-\rho_{s}\right)}\right]^{-1}
$$

The number of parts waiting to be repaired in the system $L_{q}$ is:

$$
L_{q}=\frac{p_{0} \rho^{k} \rho_{s}}{k !} \frac{\mathrm{d}}{\mathrm{d} \rho_{s}}\left(\sum_{n=1}^{\infty} \rho_{s}^{n}\right)=\frac{p_{0} \rho^{k} \rho_{s}}{k !\left(1-\rho_{s}\right)^{2}}
$$

According to the Little formula, the average repair time $T$ (including service time and waiting time) of the parts in the maintenance point is obtained:

$$
T=\frac{L_{q}+\rho}{\lambda}
$$

Then take repair time $T$ into the inventory allocation model of spare parts, a united planning method based on queuing theory and Vari-Metric model is obtained to deploy the aircraft spare parts and ground maintenance equipment.

\subsection{Solving process based on marginal analysis}

According to the relevant literature[5], it can be proved that the expectation of spare parts shortage is a monotone increasing, convex function of inventory level, so the multi-echelon inventory allocation model can be solved by the method of marginal analysis.

Step.1 Set the initial allocation of spare parts and ground maintenance equipment, which the 
number of ground maintenance equipment should be avoid the queue is lengthening.

Step.2 Calculate the marginal increment of spare parts and ground maintenance equipment, i.e., calculate the maximum value of $\Delta i=\left[E B O\left(\mathrm{~S}_{i}\right)-E B O\left(\mathrm{~S}_{i}+1\right)\right] / c_{i}$ and $\Delta k=\left[E B O\left(\mathrm{~S}_{k}\right)-E B O\left(\mathrm{~S}_{k}+1\right)\right] / c_{k}$, Increase the unit number of spare parts or ground maintenance equipment according to the maximum marginal increment.

Step.3 Calculate the total investment $\operatorname{cost} C$, if $C \leq C_{0}$, go to step.2; otherwise, end of the calculation.

\section{Numerical example}

A typical numerical example is provided to illuminate the application of our model. The maintenance resources allocation problem about the engine of Air China's aircrafts that used on American route is selected as the research object. The fleet consisted of 5 Boeing 747-8 and 10 Boeing 777-300ER aircraft, the Boeing 747-8 aircraft used on Chongqing - Beijing - San Francisco and Beijing - New York routes, the Boeing 777-300ER aircraft used on Beijing - Los Angeles, Beijing - Houston and Beijing -Washington routes. The two kinds of aircrafts were used GEnx and GE90 engine respectively, the specific parameters are shown in Table 1 and Table 2. Airport maintenance points are regarded as the Location Warehouse (LW), the company called Air China Technics are regarded as the Central Department (CD). A set of GE engine maintenance equipment at the LW worth \$1 million, and the price of maintenance equipment at the $\mathrm{CD}$ is $\$ 40$ million.

Table 1 GEnx aeroengine parameters

\begin{tabular}{|c|c|c|c|c|c|}
\hline name & $\begin{array}{c}\text { The } \\
\text { number of } \\
\text { aircraft }\end{array}$ & $\begin{array}{c}\text { Installed } \\
\text { number }\end{array}$ & $\begin{array}{c}\text { Flight } \\
\text { hours/Hour }\end{array}$ & $\begin{array}{c}\text { Mean Time } \\
\text { Between } \\
\text { Failure/Hour }\end{array}$ & Cost/USD \\
\hline GEnx-2B67 engine & 5 & 4 & \multicolumn{2}{|c|}{2920} & \multicolumn{2}{|c|}{4000} & $1.7 \mathrm{M}$ \\
\hline $\begin{array}{c}\text { Order and ship } \\
\text { time(internal)/day }\end{array}$ & $\begin{array}{c}\text { Order and ship } \\
\text { time(abroad)/day }\end{array}$ & $\begin{array}{c}\text { Average } \\
\text { repair } \\
\text { time/day }\end{array}$ & $\begin{array}{c}\text { Repair } \\
\text { probability at } \\
\text { the } \\
\text { LW(internal) }\end{array}$ & $\begin{array}{c}\text { Repair probability } \\
\text { at the LW(abroad) }\end{array}$ \\
\hline 30 & 50 & 60 & 0.2 & 0.1 \\
\hline
\end{tabular}

Table 2 GE90 aeroengine parameters

\begin{tabular}{|c|c|c|c|c|c|}
\hline name & $\begin{array}{c}\text { The } \\
\text { number of } \\
\text { aircraft }\end{array}$ & $\begin{array}{c}\text { Installed } \\
\text { number }\end{array}$ & $\begin{array}{c}\text { Flight } \\
\text { hours/Hour }\end{array}$ & $\begin{array}{c}\text { Mean Time } \\
\text { Between } \\
\text { Failure/Hour }\end{array}$ & Cost/USD \\
\hline GE90-115B engine & 10 & 2 & \multicolumn{2}{|c|}{3942} & \multicolumn{2}{|c|}{4000} & $27.5 \mathrm{M}$ \\
\hline $\begin{array}{c}\text { Order and ship } \\
\text { time(internal)/day }\end{array}$ & $\begin{array}{c}\text { Order and ship } \\
\text { time(abroad)/day }\end{array}$ & $\begin{array}{c}\text { Average } \\
\text { repair } \\
\text { time/day }\end{array}$ & $\begin{array}{c}\text { Repair } \\
\text { probability at } \\
\text { the } \\
\text { LW(internal) }\end{array}$ & $\begin{array}{c}\text { Repair probability } \\
\text { at the LW(abroad) }\end{array}$ \\
\hline 30 & 50 & 90 & 0.2 & 0.1 \\
\hline
\end{tabular}

Through the establishment of the joint allocation model proposed by this paper, the method of marginal analysis is adopted to get the fleet availability. Finally, we obtained the allocation scheme with the fleet availability of 0.96 under the investment expenses of $\$ 684$ million. The allocation scheme of spare parts and ground maintenance equipment are shown in Table 3 and Table 4 . The curves about expectation of spare parts shortage and fleet availability that are changed over investment cost as shown in Figure 2.

Table 3 the number of spare parts

\begin{tabular}{|c|c|c|c|c|c|}
\hline Location & Beijing & Chongqing & $\begin{array}{c}\text { San } \\
\text { Francisco }\end{array}$ & New York & $\begin{array}{c}\text { Air China } \\
\text { Technics }\end{array}$ \\
\hline The spare parts number & 2 & 0 & 1 & 2 & 6 \\
\hline
\end{tabular}




\begin{tabular}{|c|c|c|c|c|c|}
\hline of GEnx engine & & & & & \\
\hline location & Beijing & $\begin{array}{c}\text { Los } \\
\text { Angeles }\end{array}$ & Houston & Washington & $\begin{array}{c}\text { Air China } \\
\text { Technics }\end{array}$ \\
\hline $\begin{array}{c}\text { The spare parts number } \\
\text { of GE90 engine }\end{array}$ & 2 & 1 & 1 & 1 & 7 \\
\hline Cost & \multicolumn{5}{|c|}{ \$517 million } \\
\hline
\end{tabular}

Table 4 the number of maintenance equipment

\begin{tabular}{|c|c|c|c|c|c|}
\hline Location & Beijing & Chongqing & $\begin{array}{c}\text { San } \\
\text { Francisco }\end{array}$ & New York & $\begin{array}{c}\text { Air China } \\
\text { Technics }\end{array}$ \\
\hline $\begin{array}{c}\text { The number of } \\
\text { maintenance } \\
\text { equipment }\end{array}$ & 1 & 1 & 1 & 1 & 4 \\
\cline { 2 - 5 } & Los Angeles & Houston & Washington & \\
\hline Cost & 1 & 1 & 1 & \multicolumn{3}{|c|}{ \$167 million } \\
\hline
\end{tabular}
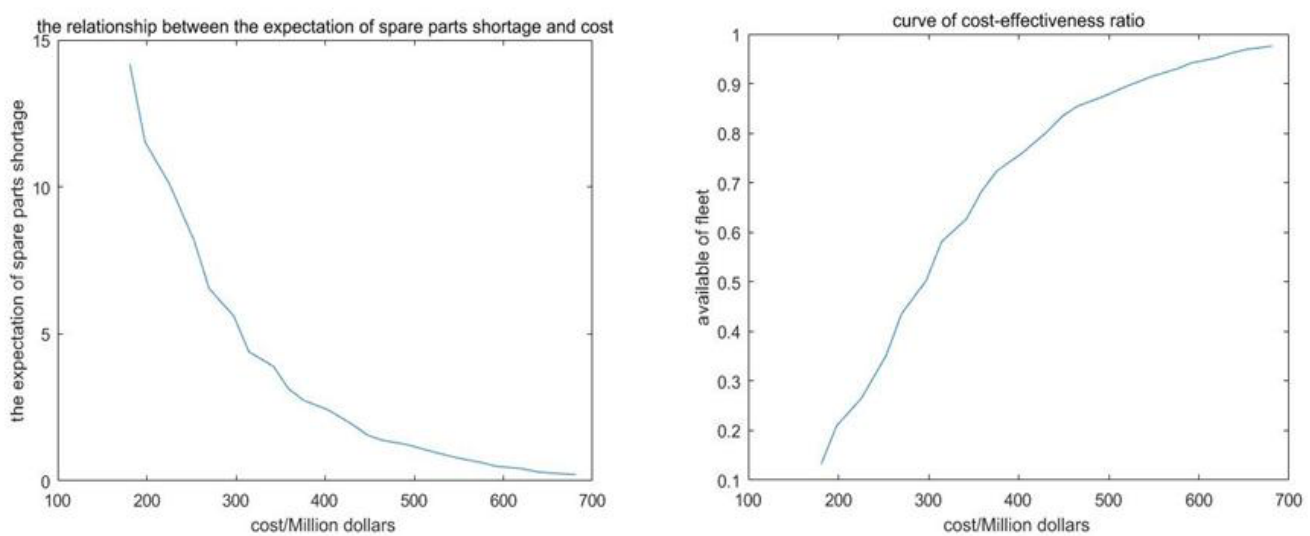

Figure 2 The curves of expectation of spare parts shortage and fleet availability changed over cost

The results show that the following two points: (1) The fleet availability increased with investment cost, but the growth trend is more and more slow. So it's usually to maintain the fleet availability between 0.85-0.95 in engineering applications, some important parts such as the engine can be maintained at $0.95-0.97$. (2) The lack of ground maintenance equipment caused significantly impact on spare parts shortage, but when the maintenance equipment achieve a certain amount, the influence to spare parts from the number of maintenance equipment will decrease sharply. So it's impossible to improve the fleet availability through continue to increase the number of maintenance equipment.

If we do not consider the impact of maintenance equipment, and using the assumption of infinite maintenance capability, we can get the engine spare parts inventory scheme under the same availability (see table 5).

Table 5 the number of spare parts

\begin{tabular}{|c|c|c|c|c|c|}
\hline Location & Beijing & Chongqing & $\begin{array}{c}\text { San } \\
\text { Francisco }\end{array}$ & New York & $\begin{array}{c}\text { Air China } \\
\text { Technics }\end{array}$ \\
\hline $\begin{array}{c}\text { The spare parts number } \\
\text { of GEnx engine }\end{array}$ & 2 & 0 & 1 & 1 & 4 \\
\hline location & Beijing & Los Angeles & Houston & Washington & $\begin{array}{c}\text { Air China } \\
\text { Technics }\end{array}$ \\
\hline $\begin{array}{c}\text { The spare parts number } \\
\text { of GE90 engine }\end{array}$ & 2 & 1 & 1 & 1 & 4 \\
\hline Cost & \multicolumn{3}{|c|}{ \$397.5 million } \\
\hline
\end{tabular}

Observing the allocation of engine spare parts under infinite maintenance capacity, we found that the effect of repair capacity for spare parts allocation scheme is mainly reflected in the CD maintenance point. This is because the CD maintenance point has a heavy maintenance task, fault parts repaired quickly and translated into stock of spare parts timely under the infinite maintenance 
capacity assumption, thereby the demand for the number of spare parts at the CD is reduced.

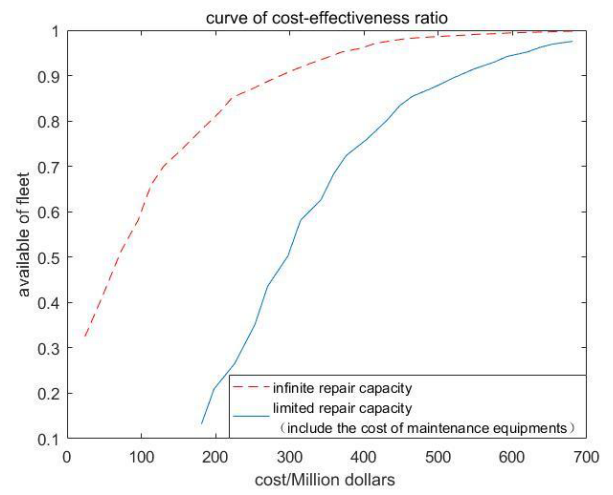

Figure 3 comparison of limited and infinite repair capacity

Due to the limited repair ability and ground equipment costs, there is a big gap of fleet availability in the same cost from whether to consider the ground maintenance equipment (see Figure 3). But with the increase in investment costs, the gap between the two is reduced gradually. The main reason is that after the maintenance equipment reached a certain number, it's influence on fleet availability decreased sharply. At this time, spare parts become the decisive element of fleet availability.

To sum up, the united allocation model proposed in this paper can effectively solve the planning problem for spare parts and ground maintenance resources.

\section{Summary}

For the current study, the spare parts inventory allocation model has the problem of over estimating the maintenance capability. In this paper, we take the allocation problem of aeroengine maintenance resources as an example, focusing on the use of $\mathrm{M} / \mathrm{M} / \mathrm{c}$ queuing model to analyze the effects of repair time from the number of maintenance equipment. A united planning model, which is used to allocate maintenance resources for civil aircraft is put forward, and the model can be solved by marginal analysis method.

The research of this paper provides an effective method to reasonable allocating the maintenance resources for civil aircraft. The method can not only reduce maintenance cost, improve support efficiency of civil aircraft operation, but also enrich the theory, method and technology of maintenance resources allocation for civil aircraft. It has important application value in engineering for civil aircraft in using and development. Based on the current research, the future will consider the allocation of civil aircraft maintenance resources under the imperfect maintenance case.

\section{Acknowledgements}

The work is supported by the National Natural Science Foundation of China (No. 10577015) and Special Scientific Research Project of Civil Aircraft(MJZ-2014-F-06)

\section{References}

1. Sherbrooke C C, Operations Research, 16, 122-141 (1966)

2. Mcclain J O, Maxwell W L, Muckstadt J A, et al, Management Science, 30, 772-773 (1984)

3. Graves S C, Management Science, 31, 1247-1256 (1985)

4. J Xu, H Zuo, L Sun, Information Technology Journal, 13 (2014)

5. Costantino F, Gravio G D, Tronci M, Reliability Engineering System Safety, 119, 95-101 (2013) 